Programmes were designed and delivered by people with different professional backgrounds which influenced content and format. Examples of mutual support between community safety teams in neighbouring counties were found. Programme evaluation was variable.

Conclusions Children and young people in the UK are receiving variable fire safety education and training. Devolved responsibility for programmes and financial pressures on Fire and Rescue Services are thought to contribute to differences in access, content and format. Examples of innovative programmes delivered by motivated teams were identified, though there are opportunities for greater sharing of best practice and developing evidence of effectiveness. These findings have the potential to inform future research and practice in fire safety education across the UK.

\section{RISK, MOTIVES AND PREVENTION OF DELIBERATELY SET FIRES}

Tuula Kekki. The Finnish National Rescue Association, Finland

\subsection{6/injuryprev-2016-042156.840}

Background The amount of fires, such as the deliberately set fires has decreased in recent years. Regardless arsons ( 2000) seems to be a permanent phenomenon in Finnish society. Even if setting a fire haven't used in political, racist or radicalised reasons, they cause every year remarkable costs, danger of life and health and personal suffer also for outsiders.

Methods This research examined deliberately set fires based on reports from the electronic resource and accident statistics system (PRONTO) of the Emergency Services, investigation reports from the electronic investigation and executive assistance system (Patja) of the police and telephone interviews and an email survey of the representatives of the Rescue Services and the police.

The qualitative data was gathered by analysing and categorising the typical targets, methods, severity of fires, situational elements, motives, perpetrators and other descriptive information. The main idea was to examine high-risk targets and areas as well as potential perpetrators and victims.

Results Research shows that deliberately set fires occur in our everyday living environment: homes, yards, parks, nearby woods and streets. The most common type of goods set on fire are miscellaneous articles: cast-off and abandoned "nobody's property". The second most common type are refuse shelters and containers, and paper and clothes collection boxes.

Of all buildings set on fire, every third one was in residential use at the time of the fire.

The control and prevention of deliberate fires is difficult by means of supervision, as the underlying causes include vandalism, curiosity, revenge, jealousy, the seeking of a financial benefit, suicidal behaviour and mental problems. A portion of the fires set by young people are caused by thoughtlessness and curiosity, some are the result of more serious, accumulated problems. Arson performs also as an extremely goal-orientated form of aggressive or destructive behaviour.

Conclusions The presentation concentrates on risk targets and the personal properties of fire-setters. By analysing different motives, intentions and situational conditions is possible to find out some relevant practices to combat deliberately set fires.

\section{HUMAN BEHAVIOUR IN THE FIRE CASES}

Tuula Kekki. The Finnish National Rescue Association, Finland

10.1136/injuryprev-2016-042156.841

Background Most of fires are caused by human activity: by accident or deliberately. People may handle incautiously electronical equipment, fire place, grill or other burning element, like matches, ash or cigarettes. They might set a fire too near the buildings, use too much charcoal lighter fluid or forgot to suppress the fire carefully. Population surveys shows that almost every responders have smoke alarm. The experience and daily observation of fire fighters this is not true especially in the cases where inhabitant has injured or dead.

Methods Data consist of the electronic resource and accident statistics system (PRONTO) of the Emergency Services and interviews of the representatives of the Rescue Services.

Results This research will start in spring 2016. Research is concentrating on human action which leads in catching fires and how people are behaving in the case on fire. More specific, the research will find out what are the most general causes of fires and what situations and circumstances are most potential for firerelated accidents.

More detailed analysis will be made on fires caused by minors, immigrants, older people and patients of institutional care. It's also interesting to investigate the circumstances where persons have injured or dead - why they didn't manage to suppress the fire or escape from the burning space.

Conclusions Results will benefit many authors as well researchers and planner officers to develop different safety campaigns, improve safety culture and housing safety.

\section{GENDER DIFFERENCES IN BURNS MANAGEMENT: A CROSS-SECTIONAL STUDY FROM EMERGENCY CENTRES, SOUTH AFRICA}

${ }^{1}$ Lisa Blom, ${ }^{1}$ Anders Klingberg, ${ }^{1,2}$ Lucie Laflamme, ${ }^{3}$ Lee Wallis, ${ }^{1}$ Marie Hasselberg. ${ }^{1}$ Karolinska Institutet, Sweden; ${ }^{2}$ University of South Africa, South Africa; ${ }^{3}$ Stellenbosch University, South Africa

\subsection{6/injuryprev-2016-042156.842}

Background Gender differences have been reported both in exposure to and outcome of burn injuries. Whereas the general gender distribution of burns is relatively well known, few studies have examined gender differences in incidence and management of burns for different burn mechanisms in sub-Saharan Africa.

Methods The study is cross sectional and based on case reports of patients seeking care for a burn injury at Emergency Centres in eight health care facilities in the Western Cape Province, South Africa between June 2012 and May 2013 (n = 1915). Gender specific incidence rates were compiled for age groups $0-4,5-9$, $10-14,15-19,20-54$ and $55+$. Differences in proportions in men and women were examined for AIS, length of stay and disposition. All analyses were stratified by burn mechanism.

Results Children 0-4 years have the highest incidence of burns with boys and girls relatively equally affected. Gender differences in burn incidence are found in ages 20 years and older. Men 55 years and older have a higher risk compared to women for hot liquid burns whereas men aged 20-54 have a higher risk of fire burns. While no gender differences in children are observed in injury management, adult men are significantly more transferred than women (all burn mechanisms aggregated) while women with both hot liquid and fire burns are treated as outpatients to a 
higher extent. No gender difference in AIS or length of stay are found among adults.

Conclusions Even though burn incidence is highest among children, gender differences in burn incidence and management are mainly visible in adults. Results about men being transferred and women treated as outpatients to a higher extent in spite of similar AIS raise the question of hidden gender biases in the healthcare.

\section{RISK FACTORS FOR UNINTENTIONAL HOUSE FIRE INCIDENTS, INJURIES AND DEATHS: A SYSTEMATIC REVIEW}

'Samantha L Turner, ${ }^{1}$ Rhodri Johnson, ${ }^{2}$ Alison L Weightman, ${ }^{1}$ Sarah E Rodgers, ${ }^{3}$ Geri Arthur, ${ }^{1}$ Rowena Bailey, ${ }^{1,3}$ Ronan A Lyons. ${ }^{1}$ Farr Institute Swansea University, UK; ${ }^{2}$ Specialist Unit for Review Evidence, Cardiff University, UK; ${ }^{3}$ Public Health Wales NHS Trust, UK

\subsection{6/injuryprev-2016-042156.843}

Background Unintentional house fires appear to be reducing but remain a serious public health concern, disproportionately affecting certain groups in population. To ensure preventative measures reach those at greatest risk, it is vital that risk factors for unintentional fires are identified; particularly in light of recent funding cuts in many Fire Services across high-income countries. However, the last review to be conducted in this area was undertaken over 15 years ago.

Methods To synthesise the evidence on risk factors for unintentional house fires, a range of bibliographic databases and grey literature were searched until October 2015. Key journals and reference lists were also hand-searched. To ensure the magnitude of risk could be quantified for each factor, only those studies that contained a comparison group, and undertook appropriate statistical analyses were included. A best evidence synthesis was undertaken instead of a meta-analysis due to study heterogeneity.

Results This review identified 12 studies that investigated a variety of potential risk factors and outcomes that fulfilled the inclusion criteria. None of the identified studies were deemed high quality, but the available evidence suggests the following factors may be associated with fire risk: age, gender, socio-economic status, race/ethnicity, disability, household ownership, household composition, property characteristics, smoking, alcohol/drug use, fire safety practices and marital status. It also appears that whilst older and disabled residents are more likely to suffer an injury or fatality in the event of a fire; they are less likely to ignite a fire in the first instance.

Conclusions There is a surprising paucity of high quality studies examining risk factors for house fire incidents, injuries and deaths. Further high quality studies, adopting standardised methods are required to permit synthesis, and to develop a firmer understanding of unintentional house fire risk factors.

\section{TREND AND CURRENT CHARACTERISTICS OF BURN FROM CHINESE NATIONAL INJURY SURVEILLANCE SYSTEM FROM 2006 TO 2013}

Ye Jin, Leilei Duan, Yuan Wang, Pengpeng Ye, Xiao Deng, Xin Gao, Yuliang Er, Cuirong Ji. $N C N C D$, China CDC

10.1136/injuryprev-2016-042156.844

Objective To understand the trend and current characteristics of burn in china by using data from the Nation Injury Surveillance
System (NISS) and the results of the study would provide basis of corresponding intervention strategies and decision-making.

Method Descriptive analysis was applied to display characteristics of burn in 2013 and trend of burn from 2006 to 2013.

Results The number of burn increased from 2006 to 2013 while the proportion of burn among unintentional injuries did not change much during these years. Number of burn in male was higher than in female in the same years. However, proportion of burn among unintentional injuries in female was always slightly higher than that in male. The proportion of burn was quite high in young children comparing with other age groups. In 2013, the proportion of burn in 1-4 years old children was $8 \%$, which was much higher than that in other ages (Average proportion for all ages was $2 \%$ ). Burn ranked the third cause of child unintentional injuries for children in the age of $1-4 \mathrm{y}$. The major place that burn took place was home (64\%). Recreation activates (54\%) was the main way of causing the burn to happen. The most common parts of body that burn involved were upper limbs (34\%) and low limbs (27\%). $73 \%$ of burns were minor and $75 \%$ went home after the treatment. The proportion of serious burn had negative correlation with the level of education.

Conclusion Even though burn ranked first some places among all injuries. It should not be ignored, especially for young children. Caring children by caregivers was important for preventing child burn.

\section{COST-EFFECTIVENESS ANALYSIS IN FIRE PREVENTION}

Laine Tuomas. University of Tampere, Finland

\subsection{6/injuryprev-2016-042156.845}

Background The recent cuts in public resources has put also the effectiveness of fire prevention programs under closer scrutiny. Fire prevention is one of the main functions of the regional fire departments and under growing rivalry for declining recourses. Thus, better methods in increasing or optimising effectiveness are desperately needed. This research is the first serious attempt to apply CEA in evaluating the effectiveness of fire prevention program, in Finland and internationally.

Methods Cost-effectiveness analysis (CEA) is an economic method for comparing the relative costs and effects of alternative or exclusive courses of actions. CEA is widely used in evaluating various public programs, such as health and social services, but it has not been in standard use in evaluating fire prevention programs. This is partly because of the ambiguity of the expected impacts, but also because of shortcomings in data collection and process designs.

Results The firms aim is to detect general feasibility of CEA in decision making under budget constraints, taking into account all welfare and equity effects and other externalities involved. This provides methodological guidelines for implementing CEA in evaluating and optimising the effectiveness of fire protection. Second, the study aims to test the virtues of CEA by implementing it in selected case studies. This yields practical guidelines and processual suggestions for information based management in fire services.

Conclusions The research is still a work in progress. The conclusions of the analysis is expected to be completed by the end of spring 2016. 